\title{
Role of Activated Carbon Precursor for Mercury Oxidation and Removal: Oxidized Surface and Carbene Site Interaction
}

\author{
Regina Rodriguez *, Domenic Contrino and David Mazyck
}

Citation: Rodriguez, R.; Contrino, D. Mazyck, D. Role of Activated Carbon Precursor for Mercury Oxidation and Removal: Oxidized Surface and Carbene Site Interaction. Processes 2021, 9, 1190. https://doi.org/ $10.3390 / \operatorname{pr} 9071190$

Academic Editors: Maria Jose Martin de Vidales and Avelino Núñez-Delgado

Received: 4 June 2021

Accepted: 30 June 2021

Published: 8 July 2021

Publisher's Note: MDPI stays neutral with regard to jurisdictional claims in published maps and institutional affiliations.

Copyright: (c) 2021 by the authors. Licensee MDPI, Basel, Switzerland. This article is an open access article distributed under the terms and conditions of the Creative Commons Attribution (CC BY) license (https:// creativecommons.org/licenses/by/ $4.0 /)$.
Department of Environmental Engineering Sciences, University of Florida, 314 AP Black Hall, Gainesville, FL 32611, USA; dcontrino@ufl.edu (D.C.); dmazyck@ufl.edu (D.M.)

* Correspondence: reggie17r@ufl.edu

\begin{abstract}
Activated carbon (AC) is widely accepted for the removal of inorganic contaminants like mercury; however, the raw material used in the production of activated carbon is not always taken into consideration when evaluating its efficacy. Mercury oxidation and adsorption mechanisms governed by carbene sites are more likely to occur when graphitic-like activated carbons (such as those produced from high-ranking coals) are employed versus lignocellulosic-based ACs; this is likely due to the differences in carbon structures where lignocellulosic materials are less aromatic. In this research, the team studied bituminous coal-based ACs in comparison to coconut shell and wood-based (both less aromatic) ACs for elemental mercury removal. Nitric acid of $0.5 \mathrm{M}, 1 \mathrm{M}$, and $5 \mathrm{M}$ concentrations along with $10 \mathrm{M}$ hydrogen peroxide were used to oxidize the surface of the ACs. Boehm titrations and FTIR analysis were used to quantify the addition of functional groups on the activated carbons. A trend was observed herein, resulting in increasing nitric acid molarity and an increased quantity of oxygen-containing functional groups. Gas-phase mercury removal mechanisms including physisorption, oxygen functional groups, and carbene sites were evaluated. The results showed significantly better elemental mercury removal in the gas phase with a bituminous coalbased AC embodying similar physical and chemical characteristics to that of its coconut shell-based counterpart. The ACs treated with various oxidizing agents to populate oxygen functional groups on the surface showed increased mercury removal. It is hypothesized that nitric acid treatment creates oxygen functional groups and carbene sites, with carbene sites being more responsible for mercury removal. Heat treatments post-oxidation with nitric acid showed remarkable results in mercury removal. This process created free carbene sites on the surface and shows that carbene sites are more reactive to mercury adsorption than oxygen. Overall, physisorption and oxygen functional groups were also dismissed as mercury removal mechanisms, leaving carbene-free sites as the most compelling mechanism.
\end{abstract}

Keywords: mercury; carbene; surface chemistry; surface functional groups; activated carbon

\section{Introduction}

Elemental mercury $\left(\mathrm{Hg}^{0}\right)$ can be removed by oxidation via various mechanisms (halogenated coal additives, selective catalytic reduction), from coal-fired power plant waste to energy and cement kiln flue gas and subsequent absorption within wet scrubber systems (oxidized $\mathrm{Hg}$ is soluble in water) [1-5]. However, this process simply transfers the contaminant from the air phase to the water phase, where it can eventually enter the environment. The United States Environmental Protection Agencies' upcoming effluent limitation guidelines will diminish this approach, and therefore, adsorption in the gas phase may be the preferred option. A very popular method for elemental mercury removal is via activated carbon adsorption [6-8], where the activated carbon surface serves as an oxidation and adsorption site for mercury [9-11], which creates a strong bond that is less likely to re-enter the environment. Virgin activated carbon has proven to be less than effective in high-temperature applications for elemental mercury due to mercury's high 
volatility [12]. Therefore, activated carbon manufacturers have turned to impregnation of activated carbon with halogens to enhance oxidation/adsorption [13-15], which can cause corrosion and other harmful byproducts. When impregnated activated carbons are used, the halogens on the surface of the carbon react with the mercury to oxidize into forms such as $\mathrm{K}_{2} \mathrm{HgI}_{4}$ [16] or $\mathrm{HgI}_{2}$ and $\mathrm{HgCl}_{4}{ }^{2-}$ [17]. Understanding specific mechanisms in mercury oxidation and adsorption is the aim of this study so that engineers can better utilize this technology.

Mercury removal mechanisms include both physisorption and chemisorption, but the overall reaction is predominantly chemisorption driven. Physisorption is adsorption driven by intermolecular forces on the carbon surface (van der Waals forces) and vapor condensation of constituents within carbon pores (i.e., $\mathrm{Hg}-\mathrm{Hg}$ interactions). Chemisorption implies a chemical reaction between the surface of the carbon and elemental mercury, creating a bond. Oxygen functional groups and carbene sites are regarded as the major promoters for chemisorption [18-26]. It has been shown in previous work through comparing various activated carbons with similar physical properties that surface chemistry, and specifically, carbene sites, are a highly effective $\mathrm{Hg}^{0}$ adsorption mechanism [24]. Herein, the goal was to review the current literature on the subject and further compare the effectiveness of carbene sites with oxygen functional groups.

\subsection{Physisorption}

Physical properties of activated carbon, like surface area and pore size distribution, can play a role in the adsorption process, as the sorbent must have the right pore size distribution for a contaminant to diffuse to its final adsorption sites. Physisorption is known to play a small role in the adsorption of mercury. To our knowledge, surface area and pore structures have not been correlated with mercury removal [26] outside of 2-3 studies, which only compared two carbons and drew conclusions without considering surface chemistry [11,27]. For example, Diamantopoulou et al. [11] examined two coalbased sorbents (Norit-lignite coal-based versus Calgon-bituminous coal-based) for mercury removal and claimed that in the absence of flue gas constituents (i.e., acid gases, moisture, and halogens), micropore structure and increased surface area are the strongest influences. On the other hand, Maroto-Valer et al. [28] dismissed surface area as a factor and instead claimed that oxygen functional groups lead to increased mercury adsorption. In her study, low surface area activated carbons outperformed activated carbons with higher surface areas.

\subsection{Chemisorption at a Carbene Site}

The concept of the carbene site as proposed by Radovic et al. [29,30] is shown in Figure 1. The carbene was computationally applied by Olson et al. [31-34] using theoretical modeling; he demonstrated that activated carbon could have a specific site that can accomplish both oxidation and adsorption of elemental $\mathrm{Hg}$ (the carbene). In 2004, Olson et al. [25,32] further described the mechanism in which mercury could be oxidized and bound directly with the carbon surface at the carbene site by a donation of electrons from the $\mathrm{Hg}^{0}$ to the carbene, forming an organomercury species. Olson specifically stated that activated carbon's carbene site is mostly responsible for $\mathrm{Hg}^{0}$ removal (versus other sites, such as oxygen functional groups).

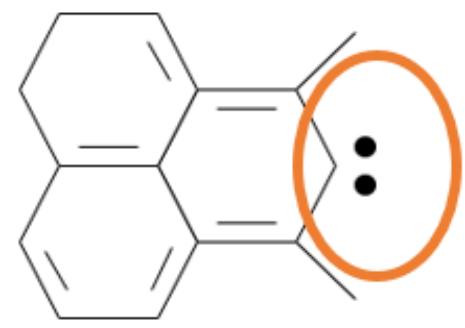

Figure 1. A lone pair of electrons situated on the edge of an aromatic sheet of carbon. This is a carbene. 
Wilcox et al. [35-38] attempted to further understand the role of the carbon surface, including the reactions at the carbene sites; however, the focus here was to evaluate the oxidation and adsorption mechanisms of oxidized mercury as $\mathrm{HgCl} / \mathrm{HgCl}_{2}$ [37] and $\mathrm{HgBr} / \mathrm{HgBr}_{2}$ [35] on the surface of the carbon. Computational results suggested that oxidized mercury compounds were the most stable to bind to the carbon surface, preferentially on the zigzag edge sites (the location of carbene sites) versus the armchair sites or basal plane. Hg-carbon bond lengths were calculated to range from 2.26 to $2.34 \AA$; and approximately $0.1 \AA$ shorter when oxygen is a nearest-neighbor atom resulting in increased stability of the Hg-C bond, further supporting Olson's initial claim. Wilcox's work also looked to identify how mercury donated its electrons in the oxidation and adsorption process, suggesting $\mathrm{Hg}^{0}$ gains electrons in the $6 \mathrm{p}$ after adsorption and donates electrons from the 5s. The electron transfer in these calculations resulted in an oxidized surface-bound $\mathrm{Hg}$ complex. This complex can also be described as organomercury carbenium, as proposed by Olson et al. [32]. It is important to note that computational studies and findings by Wilcox et al. were conducted using graphene sheet simulations under the assumption that all activated carbon surfaces would behave in a graphene-like manner. This is also how Radovic et al. originally modeled the carbene [29].

Rodriguez et al. [26] studied graphitic-like activated carbons versus lignocellulosicbased activated carbons, whose carbon rings are less aromatic for the adsorption of mercury. Activated carbon produced from bituminous coal (more aromatic) performed far better for mercury adsorption compared to the more aliphatic-derived activated carbons from coconut shells and wood. This study also hydrogen-treated carbons at $850{ }^{\circ} \mathrm{C}$ to stabilize their carbene sites by hydrogasification of functional groups and loosely bound carbon atoms resulting in condensation of the graphene layers [39]. The resulting mercury breakthrough curve for the highly aromatic bituminous coal-based AC became very similar to that of the wood- and coconut-based carbons upon stabilization. We hypothesized this phenomenon was a result of the stabilization of carbene sites which are more available in aromatic carbons. We concluded that the carbene availability of the carbon matrix was higher in the coal-based carbon; therefore, the surface was more reactive for elemental mercury removal. When activated carbon is used in an experimental or industrial setting, it cannot be assumed that all raw materials such as coconut- or wood-based activated carbons possess these graphitic and aromatic sheets.

\subsection{Oxygen Functional Groups}

The early work of Li et al. (2002 \& 2003) [18,40] was one of the first to set out to understand the mechanisms of elemental mercury adsorption at $125{ }^{\circ} \mathrm{C}$ via activated carbon surface enhancements with oxygen. In their work, two bituminous-coal-based ACs were compared to each other when oxidized with heated air $\left(420{ }^{\circ} \mathrm{C}\right)$ and room temperature nitric acid. This study also separately treated the carbons with nitrogen gas at high temperatures $\left(1200{ }^{\circ} \mathrm{C}\right)$ to remove oxygen from the surface. They concluded that oxygen functional groups, more specifically lactone and carbonyl groups, are the active sites for elemental mercury capture, while phenol and carboxyl groups are strong deterrents for elemental mercury removal.

One can offer an alternate interpretation from the results of $\mathrm{Li}$ et al. that would suggest oxygen functional groups play a less straightforward and more dominant role in mercury adsorption. Reviewing their data sets, $\mathrm{Hg}^{0}$ capacity does significantly increase by $380 \%$ for their first nitric acid-treated carbon, as do the reported lactone and carbonyl group surface concentrations. However, when the same comparison is made for their second nitric acid-treated carbon, lactone, and carbonyl functional group concentrations again increase, but conversely, the $\mathrm{Hg}^{0}$ capacity decreased by $25 \%$. The importance of carbonyl functional groups for $\mathrm{Hg}^{0}$ adsorption holds even less weight when comparing the air-treated carbons. A 540\% increased carbonyl group concentration resulted in no change in $\mathrm{Hg}^{0}$ capacity in one carbon, while $230 \%$ of carbonyl groups in the second carbon resulted in a sharp $98 \%$ decrease in $\mathrm{Hg}^{0}$ capacity. The number of functional groups created by nitric acid treatments 
and air treatments is very similar for both sorbents studied; however, the level of $\mathrm{Hg}^{0}$ was very different for the two.

Other studies suggesting strong correlations between $\mathrm{Hg}^{0}$ adsorption and oxygen functional groups include Hall et al. (1995) [41], who had described efficient chemisorption of mercury on the surface of carbon, specifically with high oxygen content at flue gas temperatures (100-300 $\left.{ }^{\circ} \mathrm{C}\right)$. Likewise, Lee and Park (2003) [42] detailed that superior elemental mercury adsorption was strongly correlated with oxygen functional groups on the carbon's surface. Padak et al. (2006) [37] further endorsed Li's proposition with measured mercury binding energies associated with lactone and carbonyl groups, specifically resulting in -10.29 and $-9.16 \mathrm{kcal} / \mathrm{mol}$, respectively.

Inconsistent with Li et al., Kwon et al. (2002) [43] had a different interpretation on chemisorption. When pyrolytic graphite was compared to bituminous coal-based activated carbon for mercury adsorption, it was proposed that physisorption was the primary mechanism at lower temperatures (i.e., below $75^{\circ} \mathrm{C}$ ), while chemisorption was the driver at high adsorption temperatures (i.e., above $75^{\circ} \mathrm{C}$ ). The removal of chemical functionalities (via nitrogen gas at $900^{\circ} \mathrm{C}$ ) from the graphite surface-enhanced mercury removal. It was proposed that for physisorption, oxygen functional groups decrease mercury adsorption due to their blocking of access for mercury to micropores, while for chemisorption, oxygen functional groups have very little impact on capture.

Based on the work from Lizzio et al. [44], it can be strongly suggested that the increase in $\mathrm{Hg}^{0}$ removal by the nitric-treated sorbents is due to the surface etching and further population of carbene sites on the two bituminous-based activated carbons (rather than an increase in oxygen functional groups). It is well understood that there must be an electron transfer (oxidation) for elemental mercury adsorption to take place. The increased number of carbene sites from surface etching would therefore create many more instances of possible oxidation, and the carbon surface may then act as a type of electrode for mercury oxidation. This then leads to an increase in adsorption.

\section{Materials and Methods}

\subsection{Physical and Chemical Characterization of Activated Carbons}

\subsubsection{Activated Carbon Raw Material}

The activated carbons used in this study to compare adsorption mechanisms were crushed and sieved to US $20 \times 30$ mesh and labeled AC-BC, AC-W, and AC-CS, respectively (Table 1). US standard mesh sizes were used to classify the material to between $0.60 \mathrm{~mm}$ and $0.85 \mathrm{~mm}$ particles (US 20 and US $30 \mathrm{mesh}$, respectively). The activated carbon raw materials used were identical to those used previously by Rodriguez et al. [26]. Additionally, powdered graphite was used to compare a low surface area highly graphitized carbon material to the high surface area activated carbons. The graphite had $99 \%$ purity and was powdered to pass through a 325 mesh (Thermofisher Scientific, Waltham, MA, USA).

Table 1. Carbon raw materials.

\begin{tabular}{cc}
\hline Sample & Raw Material \\
\hline AC-CS & Coconut Shell \\
AC-W & Wood \\
AC-BC & Bituminous Coal \\
GH & Graphite \\
\hline
\end{tabular}

\subsubsection{Surface Area, Pore Volume, and Pore Size Characterization}

Each carbon sample was subjected to a nitrogen adsorption isotherm using a Quantachrome NOVA 2200e (Boca Raton, FL, USA) under identical conditions as those previously reported [26]. The Brunauer-Emmett-Teller (BET) equation was applied to quantify surface area, the Barrett-Joyner-Halenda (BJH) equation was applied to quantify pore size distributions and mesopore volume, and total pore volume was measured through the ni- 
trogen adsorption isotherm, and average pore size was calculated through Quantachrome's proprietary software.

\subsubsection{Point of Zero Charge $\left(\mathrm{pH}_{\mathrm{pzc}}\right)$}

A modified method from the ASTM standard for contact pH (ASTM 6851) was used in which carbon samples were placed in contact with ultrapure water (Barnstead) at a 1:10 g/g ratio and rotated for $24 \mathrm{~h}$. Thereafter, the $\mathrm{pH}$ of the unfiltered solution was immediately measured. More details on the method can be found in a previous publication [26].

\subsubsection{Fourier Transformed Infrared Spectroscopy}

Infrared (IR) spectra were collected for treated and untreated sorbents on a Nicolet Magna 760 FT-IR instrument equipped with a diffuse reflectance unit. The instrument's resolution was set at $4 \mathrm{~cm}^{-1}$. Samples were weighed out at $\sim 0.9 \mathrm{mg}$ and mixed $/ \mathrm{milled}$ with $0.35 \mathrm{~g}$ of $\mathrm{KCl}$ in a Wig-L-Bug for ten seconds. The carbon/ $\mathrm{KCl}$ mixture was pressed into discs for analysis using consistent pressures for each disc. Before each measurement, the instrument was run to collect the background (using ground $\mathrm{KCl}$ ), which was then automatically subtracted from the sample spectrum.

Absorption of infrared waves at specific frequencies has been correlated to specific functional groups, and through matching the absorption frequencies to known values, characterization of the carbons can be roughly quantified. Table 2 shows an abbreviated list of oxygen-containing functional groups and their IR adsorption frequencies [45]. With the use of nitric acid treatments, it is also important to note that nitroso compounds can be detected at frequency values of about $1600 \mathrm{~cm}^{-1}$ [46].

Table 2. Infrared spectra absorptions.

\begin{tabular}{ccc}
\hline Frequency, $\mathbf{c m}^{-1}$ & Bond & Oxygen Containing Functional Groups \\
\hline $3640-3610(\mathrm{~s}, \mathrm{sh})$ & O-H stretch, free hydroxyl & alcohols, phenols \\
$3500-3200(\mathrm{~s}, \mathrm{~b})$ & O-H stretch, H-bonded & alcohols, phenols \\
$3300-2500(\mathrm{~m})$ & O-H stretch & carboxylic acids \\
$1760-1665(\mathrm{~s})$ & C=O stretch & carbonyls (general) \\
$1760-1690(\mathrm{~s})$ & C=O stretch & carboxylic acids \\
$1320-1000(\mathrm{~s})$ & C-O stretch & alcohols, carboxylic acids, esters, ethers \\
$950-910(\mathrm{~m})$ & O-H bend & carboxylic acids \\
\hline
\end{tabular}

\subsubsection{Boehm Titrations}

Titrations followed a modified Boehm Method [47] where $0.5 \mathrm{~g}$ of dried carbon samples were mixed with $0.2 \mathrm{~g}$ dried $\mathrm{KCl}$ and put in separate vials each with $0.05 \mathrm{M}$ reagent solutions of sodium hydroxide $(\mathrm{NaOH})$, sodium carbonate $\left(\mathrm{Na}_{2} \mathrm{CO}_{3}\right)$, sodium hydrogen carbonate $\left(\mathrm{NaHCO}_{3}\right)$, and hydrochloric acid $(\mathrm{HCl})$ for $2 \mathrm{~h}$ under Ultrahigh Purity $\mathrm{N}_{2}$ gas purge (Airgas). Each reagent salt or acid had at least 99\% purity.

Once mixing for $2 \mathrm{~h}$ was complete, the samples remained unfiltered and were directly titrated. Acidic solutions were titrated with $0.05 \mathrm{M} \mathrm{NaOH}$ until a $\mathrm{pH}$ of 7; volumes of $\mathrm{NaOH}$ added were recorded. Basic samples were first acidified with $0.05 \mathrm{M} \mathrm{HCl}$ to a pH of 2 , then back titrated to a $\mathrm{pH}$ of 7 with $0.05 \mathrm{M} \mathrm{NaOH}$, with the volume of $\mathrm{NaOH}$ also being recorded.

Acidic functional group concentrations of each of the four reagent solutions were calculated against volumes of $\mathrm{NaOH}$ and the reagent used. The concentrations of specific functional groups were calculated following the equations and methodology demonstrated by Fidel et al. 2013 [48]. Basic functional group concentrations were done similarly using methods described by Goertzen et al., 2010 and Oickle et al., 2010 [49,50]. Each reagent has a specific $\mathrm{pKa}$ value, which can then be used to determine the concentration of active functional groups within specific $\mathrm{pKa}$ ranges. 


\subsection{Surface Chemistry Modifications of Sorbents}

All modified activated carbons were treated as dried $20 \times 30$ mesh samples. Graphite was used in a dried powder form. Liquid treatments followed the same logical progression of stirring in solution, filtering, rinsing, and drying, as shown in Figure 1. All gas treatments were conducted in a singular stainless steel vertical furnace tube at atmospheric pressure, with enough flow of gas to fluidize the sample. A detailed description of the furnace apparatus can be found in previous work [26].

\subsubsection{Nitric Acid Treatment of Activated Carbon}

Activated carbon samples were oxidized with various doses of nitric acid $\left(\mathrm{HNO}_{3}\right)$ to increase oxygen functional groups. Three different concentrations of nitric acid solutions (i.e., $0.5 \mathrm{M}, 1 \mathrm{M}, 5 \mathrm{M}$ ) were prepared using a $70 \%$ concentrated trace metal stock solution (Thermofisher) and deionized water. Carbon ( $30 \mathrm{~g})$ was magnetically stirred in $250 \mathrm{~mL}$ of each solution at $80{ }^{\circ} \mathrm{C}$ for a period of $3 \mathrm{~h}$, as shown in Figure 2. Each mixture was then filtered through a 0.45 -micron nitro-cellulose filter paper using a vacuum pump and washed with deionized water until a constant $\mathrm{pH}$ was achieved. The samples were dried at $110^{\circ} \mathrm{C}$ for at least $12 \mathrm{~h}$ before characterization and analysis. Carbon samples having undergone nitric acid oxidation are denoted with the molarity of nitric acid used, followed by $\mathrm{HNO}_{3}$.

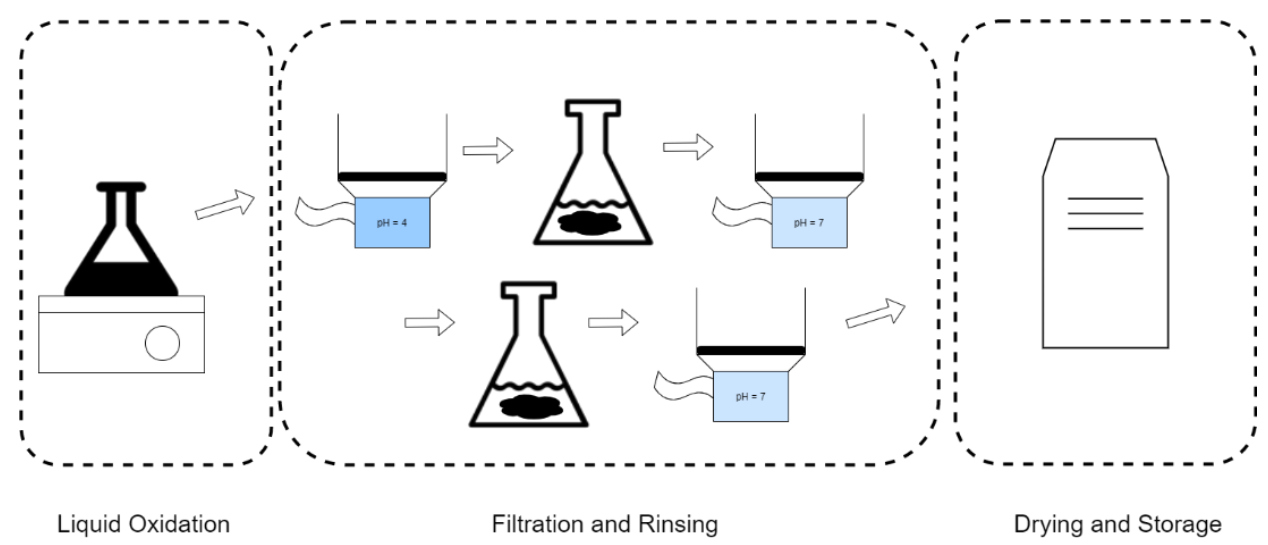

Figure 2. Diagram of liquid oxidation treatment process.

\subsubsection{Peroxide Treatment of Activated Carbon}

Peroxide oxidation of activated carbon was carried out using a similar method to nitric acid but with a $10 \mathrm{M} \mathrm{H}_{2} \mathrm{O}_{2}$ solution at room temperature for $3 \mathrm{~h}$. After each liquid oxidation, the activated carbons were filtered from solution, washed with deionized water until a constant $\mathrm{pH}$ was reached, and dried at $110^{\circ} \mathrm{C}$ for at least $12 \mathrm{~h}$ before characterization and analysis. Carbon samples having undergone hydrogen peroxide oxidation are denoted with $\mathrm{H}_{2} \mathrm{O}_{2}$.

\subsubsection{Nitrogen Gas Treatment of Activated Carbon}

Similar to previous gas treatments [26], the nitrogen treatment was carried out using ultra-high purity nitrogen gas (Airgas, $99.999 \%$ purity) at $1000{ }^{\circ} \mathrm{C}$ for $5 \mathrm{~h}$ in the configuration shown in Figure 3. After $5 \mathrm{~h}$, the furnace was turned off, and the sample was allowed to cool under the same flow of nitrogen gas. Carbon samples that were treated with nitrogen gas are denoted with NT. The carbon samples selected herein to be treated with nitrogen gas had already undergone a $5 \mathrm{M}$ nitric acid oxidation as described above. Hydrogen gas was also used in this study for the graphite sample at $850^{\circ} \mathrm{C}$ for $2 \mathrm{~h}$. 


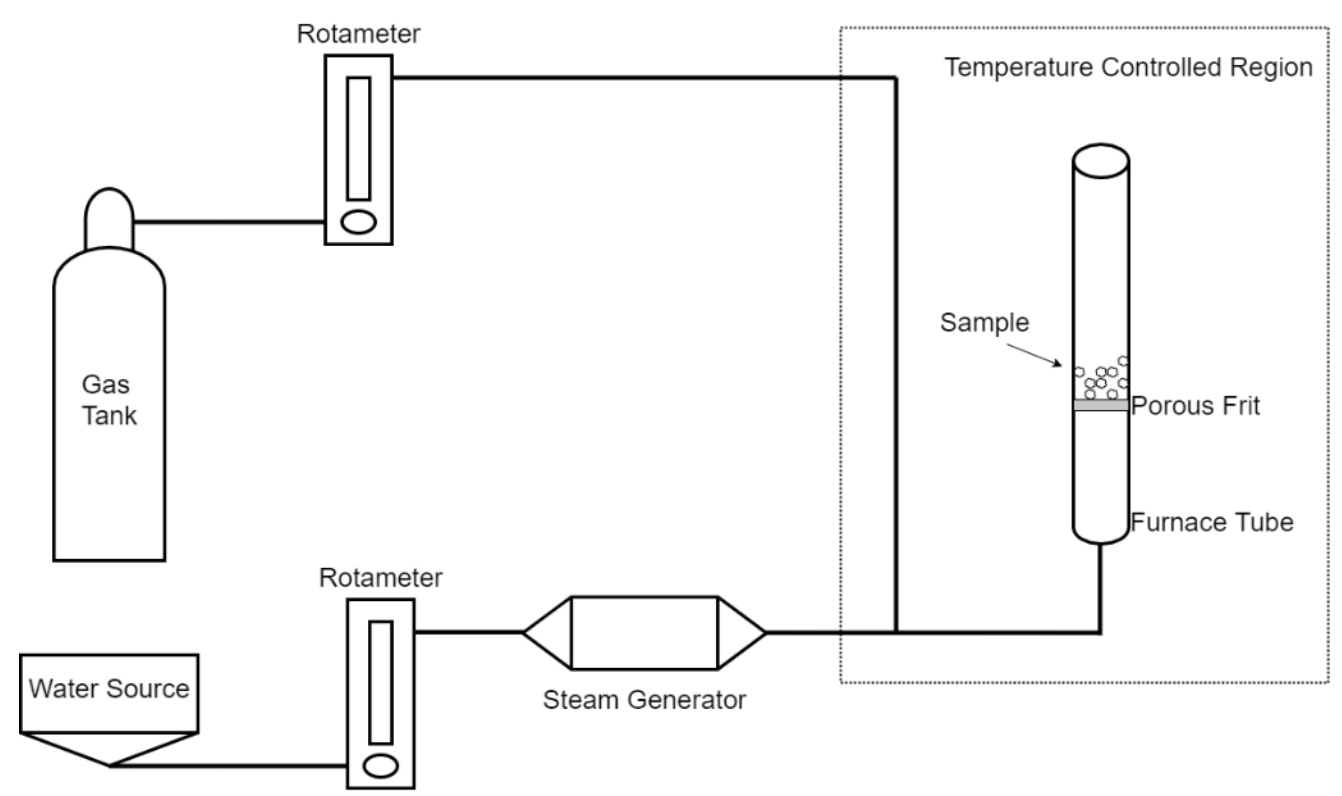

Figure 3. Furnace schematic depicting sources of gasses and steam flowing into a temperature-controlled region.

\subsection{Gas Phase Mercury Removal}

Elemental mercury $\left(\mathrm{Hg}^{0}\right)$ removal experiments were conducted under ultra-high purity nitrogen gas in a fixed bed with the flow-through reactor at room temperature $\left(25^{\circ} \mathrm{C}\right)$. Elemental mercury (VICI Metronics mercury permeation tube) was vaporized in an impinger upstream of the carbon bed and verified to be $500 \mu \mathrm{g} / \mathrm{m}^{3}$ prior to the introduction of the carbon samples. The experiments used $1 \mathrm{~g}$ of granular activated carbon or $0.5 \mathrm{~g}$ of powdered graphite. Elemental mercury was measured in real-time via atomic absorption using a Lumex Instruments RA-915+ (Solon, OH); the test stand setup used is further detailed in Rodriguez et al. [26]. Breakthrough curves have been generated with error bars reflecting the standard deviation of three individual breakthrough tests.

\section{Results \& Discussion}

\subsection{Physical Properties}

The physical and chemical properties of the resulting activated carbons are detailed in Table 3. The physical properties of oxidized activated carbon samples remained mostly unchanged from their untreated counterparts. On average, the oxidized samples, when compared to their untreated counterparts, were affected by no more than a $-3 \%$ change for characteristics such as BET surface area, average pore size, and total pore volume. $\mathrm{BJH}$ mesoporosity was more significantly affected, but still by only an average of $11 \%$ after oxidation. Therefore, any change in mercury adsorption could be attributed to chemical effects versus physical properties. As expected with the acid treatment, the $\mathrm{pH}_{\text {PZC }}$ significantly decreased on each nitric acid treatment down to acidic values in the range of 3.2 to 4.9. Peroxide treatments were mild with resulting $\mathrm{pH}_{\mathrm{pzc}}$ values of 6.8 and 7.9 for bituminous coal and wood carbons, respectively.

\subsection{Surface Chemistry Developed on Activated Carbons}

\subsubsection{Boehm Results}

The concentration of oxygen functional groups for the virgin bituminous coal-based activated carbon (AC-BC), and two acid-treated activated carbons are shown in Figure 4. Throughout each progressive increase in nitric acid molarity, the carboxyl functional group concentration increases. The lactone functional group concentration decreases with increasing nitric acid treatment molarity. This could suggest that lactonic functional groups are converted to carboxyl types upon acid treatment, as well as the addition of nitro 
compounds that contain doubly bound oxygen atoms. Phenolic groups are relatively unchanged throughout the various nitric acid treatments.

Table 3. Characterizations of treated and untreated activated carbons.

\begin{tabular}{|c|c|c|c|c|c|c|}
\hline $\begin{array}{c}\text { Carbon Raw } \\
\text { Material }\end{array}$ & $\begin{array}{l}\text { Carbon } \\
\text { Sample }\end{array}$ & $\begin{array}{l}\text { BET Surface } \\
\text { Area }\left(\mathrm{m}^{2} / \mathrm{g}\right)\end{array}$ & $\begin{array}{c}\text { Average Pore } \\
\text { Size (A) }\end{array}$ & $\begin{array}{c}\text { Total Pore } \\
\text { Volume (cc/g) }\end{array}$ & $\begin{array}{c}\text { BJH Pore } \\
\text { Volume (cc/g) }\end{array}$ & $\mathrm{pH}_{\mathrm{PZC}}$ \\
\hline \multirow{6}{*}{ Bituminous Coal } & $\mathrm{AC}-\mathrm{BC}$ & 889 & 21.1 & 0.47 & 0.09 & 8.1 \\
\hline & $\begin{array}{c}\text { AC-BC } 0.5 \mathrm{M} \\
\mathrm{HNO}_{3}\end{array}$ & 1027 & 22.3 & 0.57 & 0.11 & 4.9 \\
\hline & $\begin{array}{c}\text { AC-BC } 1 \text { M } \\
\mathrm{HNO}_{3}\end{array}$ & 889 & 21.2 & 0.47 & 0.10 & 3.7 \\
\hline & $\begin{array}{c}\mathrm{AC}-\mathrm{BC} 5 \mathrm{M} \\
\mathrm{HNO}_{3}\end{array}$ & 948 & 22.0 & 0.52 & 0.10 & 3.2 \\
\hline & $\begin{array}{c}\text { AC-BC } 10 \mathrm{M} \\
\mathrm{H}_{2} \mathrm{O}_{2}\end{array}$ & 890 & 20.8 & 0.46 & 0.07 & 6.8 \\
\hline & $\begin{array}{c}\text { AC-BC } 5 \mathrm{M} \\
\mathrm{HNO}_{3} \mathrm{NT}\end{array}$ & 949 & 22.8 & 0.54 & 0.11 & 9.8 \\
\hline \multirow{5}{*}{ Coconut Shell } & $\mathrm{AC}-\mathrm{CS}$ & 1125 & 17.5 & 0.49 & 0.03 & 8.8 \\
\hline & $\begin{array}{c}\text { AC-CS } 0.5 \mathrm{M} \\
\mathrm{HNO}_{3}\end{array}$ & 1079 & 17.1 & 0.46 & 0.02 & 4.2 \\
\hline & $\begin{array}{c}\text { AC-CS } 1 \mathrm{M} \\
\mathrm{HNO}_{3}\end{array}$ & 1007 & 17.3 & 0.44 & 0.02 & 4.0 \\
\hline & $\begin{array}{c}\text { AC-CS } 5 \mathrm{M} \\
\mathrm{HNO}_{3}\end{array}$ & 1042 & 17.0 & 0.44 & 0.01 & 3.7 \\
\hline & $\begin{array}{l}\text { AC-CS } 5 \text { M } \\
\mathrm{HNO}_{3} \mathrm{NT}\end{array}$ & 1219 & 17.3 & 0.53 & 0.02 & 9.0 \\
\hline \multirow{4}{*}{ Wood } & $\mathrm{AC}-\mathrm{W}$ & 423 & 22.3 & 0.24 & 0.05 & 8.4 \\
\hline & $\begin{array}{c}\text { AC-W } 0.5 \mathrm{M} \\
\mathrm{HNO}_{3}\end{array}$ & 405 & 23.8 & 0.23 & 0.06 & 4.4 \\
\hline & $\begin{array}{c}\mathrm{AC}-\mathrm{W} 1 \mathrm{M} \\
\mathrm{HNO}_{3}\end{array}$ & 390 & 23.8 & 0.23 & 0.06 & 4.6 \\
\hline & $\begin{array}{c}\text { AC-W } 10 \mathrm{M} \\
\mathrm{H}_{2} \mathrm{O}_{2}\end{array}$ & 475 & 22.3 & 0.26 & 0.04 & 7.9 \\
\hline
\end{tabular}

Total acidity of the carbon surface steadily increases to a maximum with the $5 \mathrm{M}$ treatments, and basicity is completely eliminated after even $1 \mathrm{M}$ nitric acid treatment.

\subsubsection{FTIR Analysis}

FTIR was used to determine the type and relative presence of the surface functional groups on the ACs. FTIR spectra over the wave numbers of $4000-400 \mathrm{~cm}^{-1}$ for AC$\mathrm{W}, \mathrm{AC}-\mathrm{CS}, \mathrm{AC}-\mathrm{BC}$, and respective nitric acid-treated $\mathrm{ACs}$ are shown in Figures 5-7. When compared with the untreated ACs, the spectrums for the nitric acid and peroxide treated samples are overall higher in magnitude, particularly in the ranges $1000-1300 \mathrm{~cm}^{-1}$, $1500-1600 \mathrm{~cm}^{-1}, 1650-1750 \mathrm{~cm}^{-1}$, and $3300-3500 \mathrm{~cm}^{-1}$. It was of interest to understand the type of functional groups present as some literature focused strongly on a correlation between carbonyl and lactone functional groups with higher mercury removal. FTIR analysis of our nitric acid-treated samples would suggest at least an increase in carboxyl groups. In all instances, $5 \mathrm{M}$ nitric acid oxidations produced the highest amount of additional functionality. Along with the addition of oxygen functional groups, nitrogen functional groups were specifically nitro compounds. Nitro compounds absorb IR spectra at the $1500-1600 \mathrm{~cm}^{-1}$ wavelength. It is clear that the $5 \mathrm{M}$ nitric acid had a strong effect in this wavelength range, and particularly in Figure 6, where the wood-based carbon also had a decrease in transmittance at the $1 \mathrm{M}$ nitric acid treatment, whereas the hydrogen peroxide treatment had no effect in this wavelength range. 


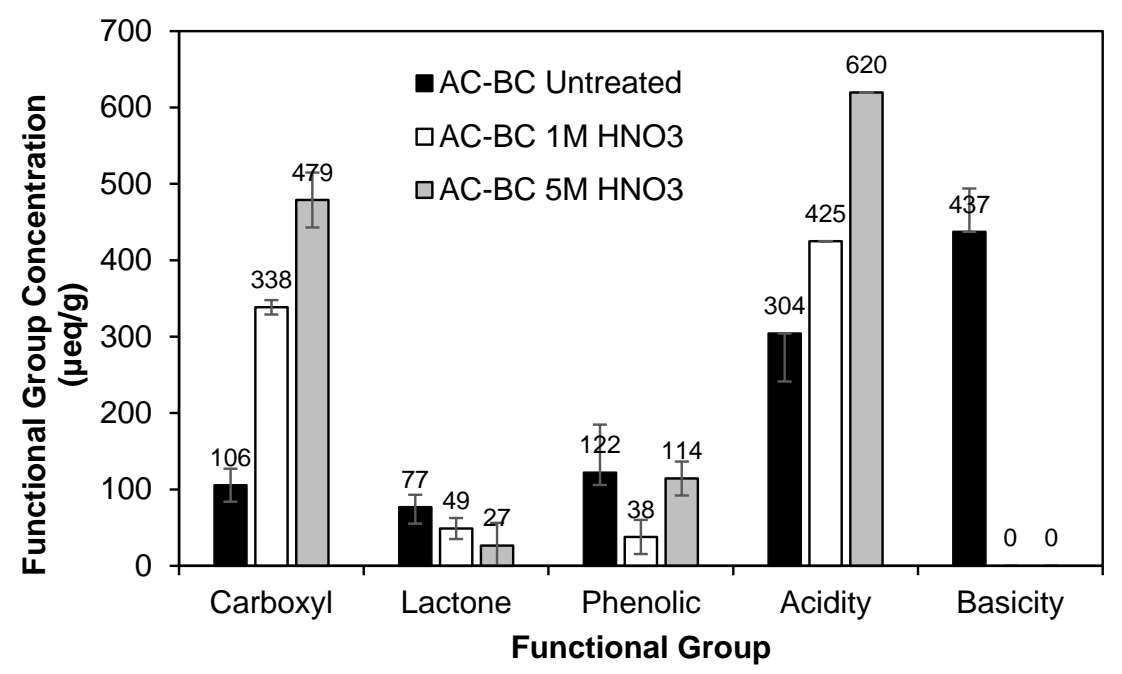

Figure 4. Boehm titrations of bituminous coal-based activated carbons and their nitric acidtreated counterparts.

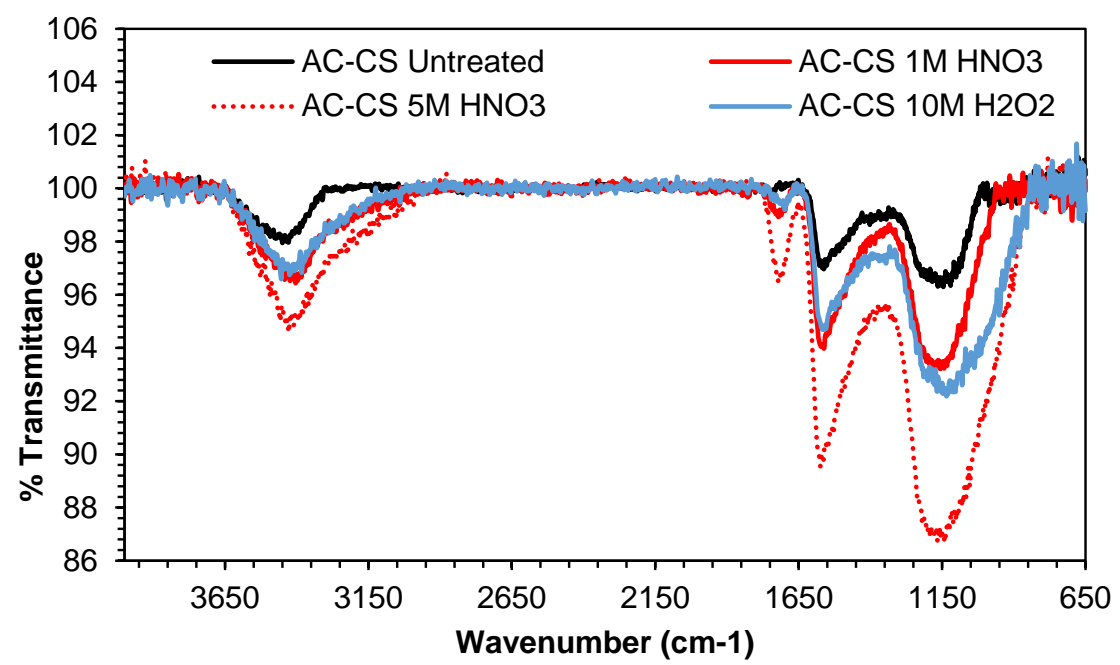

Figure 5. FTIR Spectra for AC-CS (coconut shell-based) untreated, nitric treated, and peroxide treated.

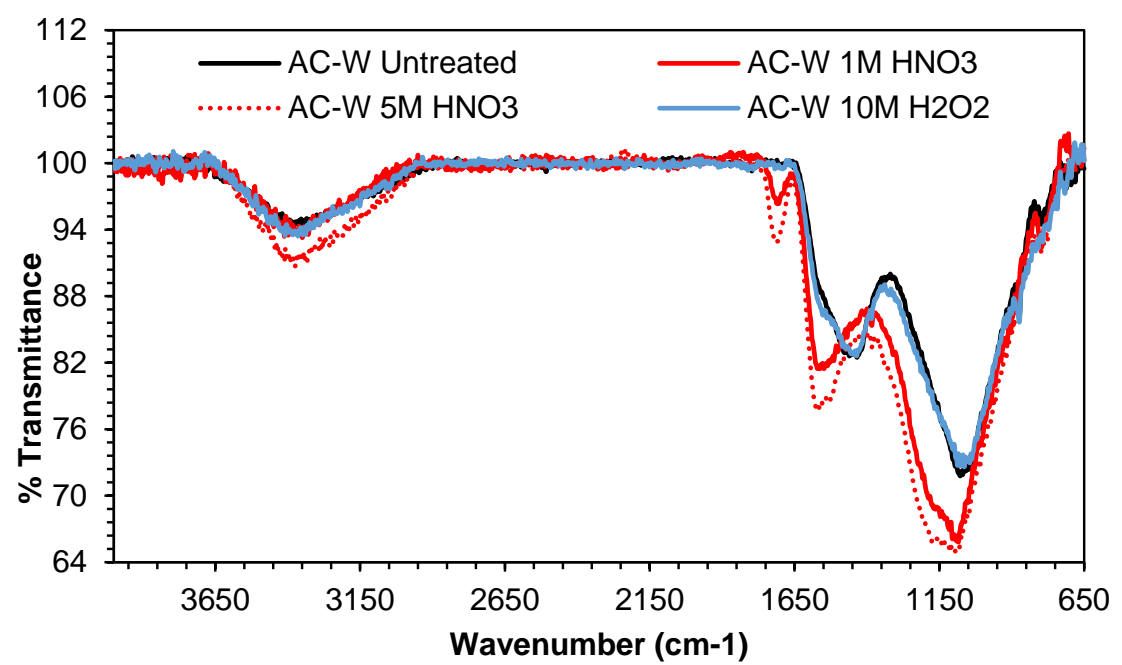

Figure 6. FTIR Spectra for AC-W (wood-based) untreated, nitric treated, and peroxide treated. 


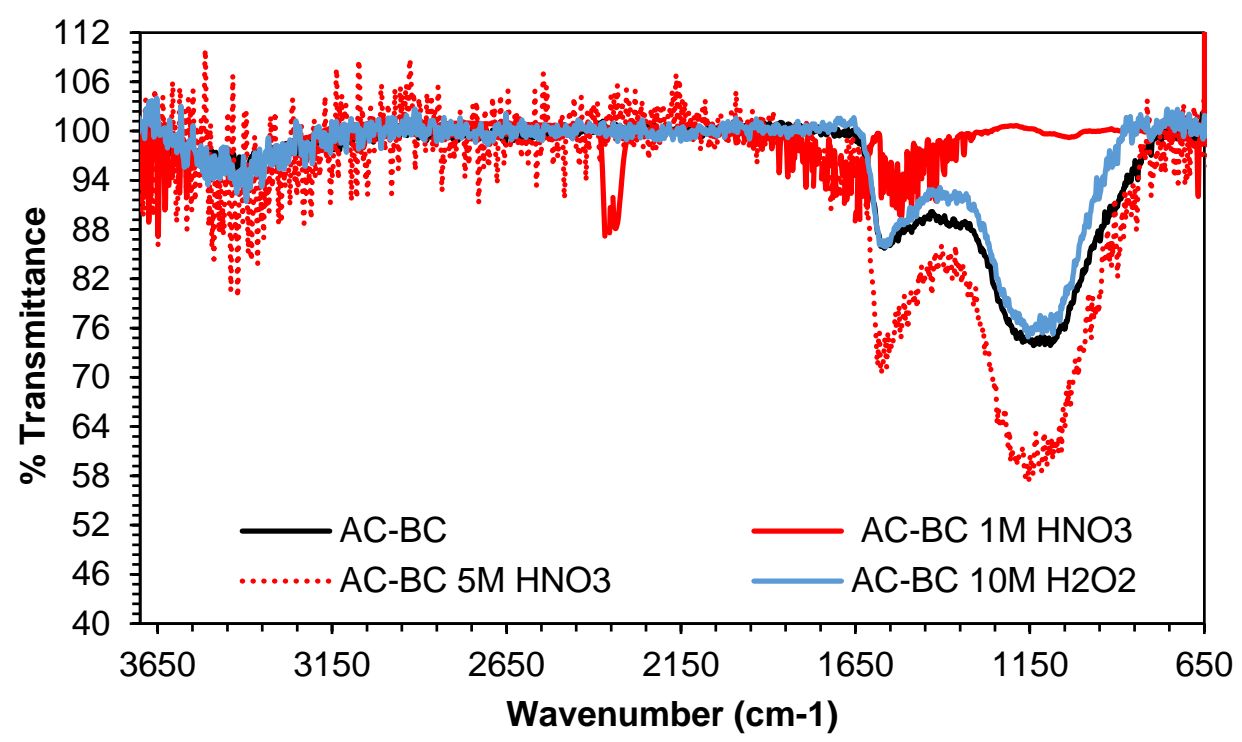

Figure 7. FTIR Spectra for AC-BC untreated, nitric treated, and peroxide treated.

The stretching and vibration peak caused by $\mathrm{C}=\mathrm{O}$ around $1665 \mathrm{~cm}^{-1}$ (indicative of carbonyls) and stretching peak caused O-H or H-bonded around $3300 \mathrm{~cm}^{-1}$ (indicative of phenols) are not as pronounced as the associated peaks at $1200 \mathrm{~cm}^{-1}$ and $1550 \mathrm{~cm}^{-1}$ which are associated with carboxylic groups. It is important to note that the analysis of carbon-based materials in this fashion is a qualitative approach that must be compared to each baseline sample (untreated). That is because the carbon materials have inherent $\mathrm{C}-\mathrm{H}-\mathrm{O}$ matrices that can prohibit comparisons across raw materials [51,52].

\subsection{Oxidation Impacts on Mercury Removal}

\subsubsection{Nitric Acid Oxidation Treatments}

Undeniably, the literature makes a strong case for the role of oxygen functional groups on the removal of elemental mercury, and therefore it cannot be overlooked $[18,19,26,50,51$, 53,54]. Commonly, nitric acid treatments are used due to their relative ease and ability to control the intensity of oxidation and to result in surface chemistry (i.e., through varying temperatures, reaction times, and acid molarity).

One disadvantage of treating with nitric acid detailed in the literature is that the pore structure of the carbon may be considerably changed [47]; however, we did not experience that in this work as both the pore volume and pore size remained very similar with all treatments. This outcome provided an opportunity to compare the differences in $\mathrm{Hg}^{0}$ removal based on the changes in surface chemistry rather than that of physical properties.

Nitric acid substitution reactions on the carbon surface typically allow for the addition of oxygen or nitrogen onto edge sites of the carbon matrix. Typically, for more aromatic structures such as that of bituminous coal, the substitution allows for more oxygen addition than nitrogen [55]. The increase in oxygen functional groups, as shown through Boehm titrations and FTIR analysis, suggest that the coconut shell-activated carbon may also have been dominantly oxygenated, while the wood-based may have been more nitrogenated.

Each sample was analyzed to determine the amount of $\mathrm{Hg}^{0}$ removed from the gas phase by the sorbent. Breakthrough curves for the lowest molarity nitric treated ACs are shown in Figure $8\left(0.5 \mathrm{M} \mathrm{HNO}_{3}\right)$. All of these oxidized samples increased their $\mathrm{Hg}^{0}$ removal. 


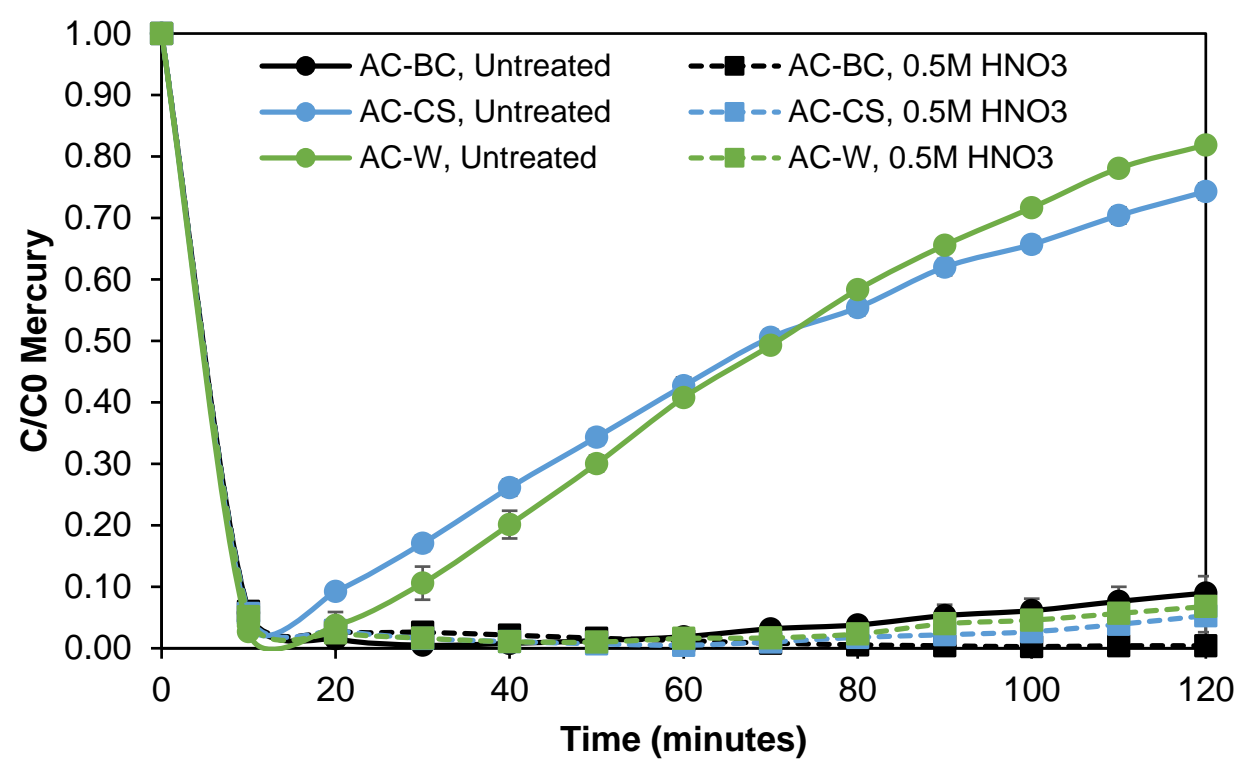

Figure 8. Treated and untreated activated carbon's removal of mercury over time.

The mercury removal results shown in Figure 8 could suggest that oxygen functional groups are important for the adsorption of elemental mercury. However, when comparing the $0.5 \mathrm{M} \mathrm{HNO}_{3}$ treated $\mathrm{AC}$ to $1 \mathrm{M} \mathrm{HNO}_{3}$ treated $\mathrm{AC}$ in the coconut-based carbon treatments (Figure 9), the $1 \mathrm{M}$ and $5 \mathrm{M} \mathrm{HNO}_{3}$ treated carbons performed worse for mercury adsorption than the $0.5 \mathrm{M} \mathrm{HNO}_{3}$ treated carbon. If oxygen functional groups were the driver, we would have expected an increase in mercury removal with an increase in nitric molarity since the Boehm results indicated an increase in oxygen functional groups. Similarly, the same was observed for $\mathrm{AC}-\mathrm{BC}$; the $5 \mathrm{M} \mathrm{HNO}_{3}$ sample performed worse than the $1 \mathrm{M} \mathrm{HNO}_{3}$ (Figure 10).

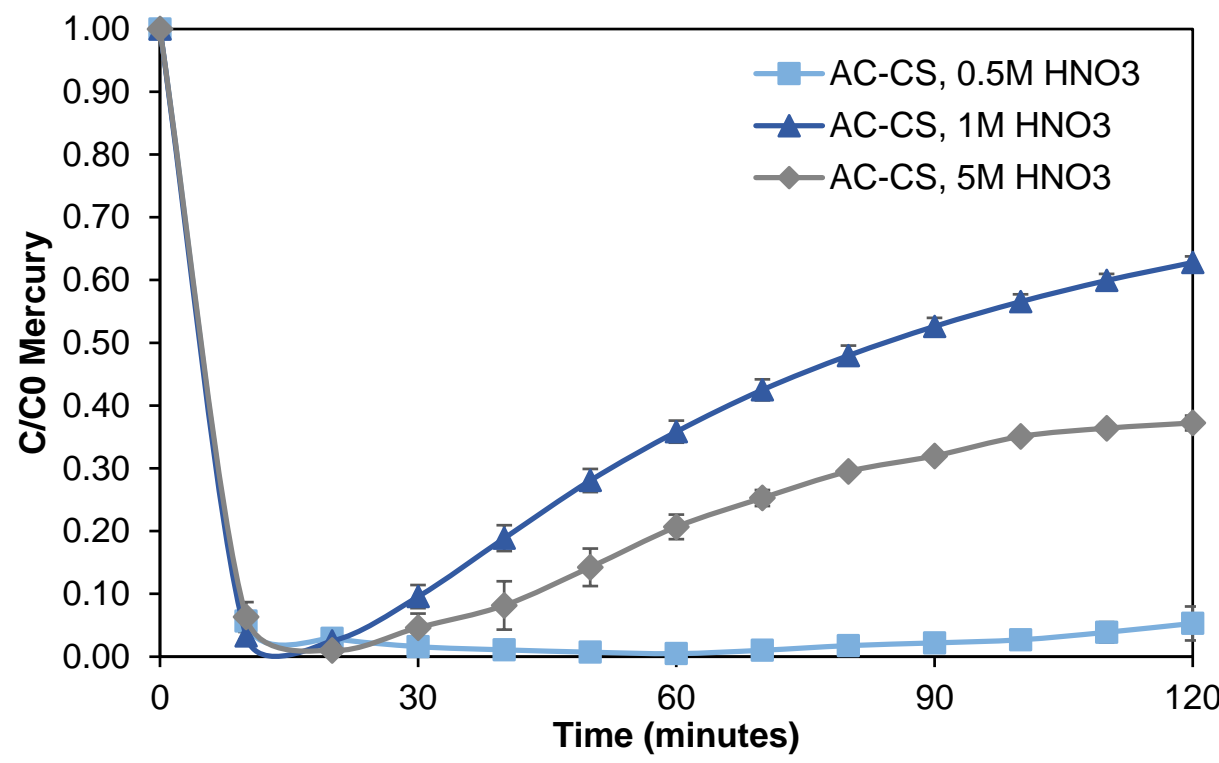

Figure 9. Mercury removal for coconut-based activated carbons treated with increasing nitric acid concentrations. 


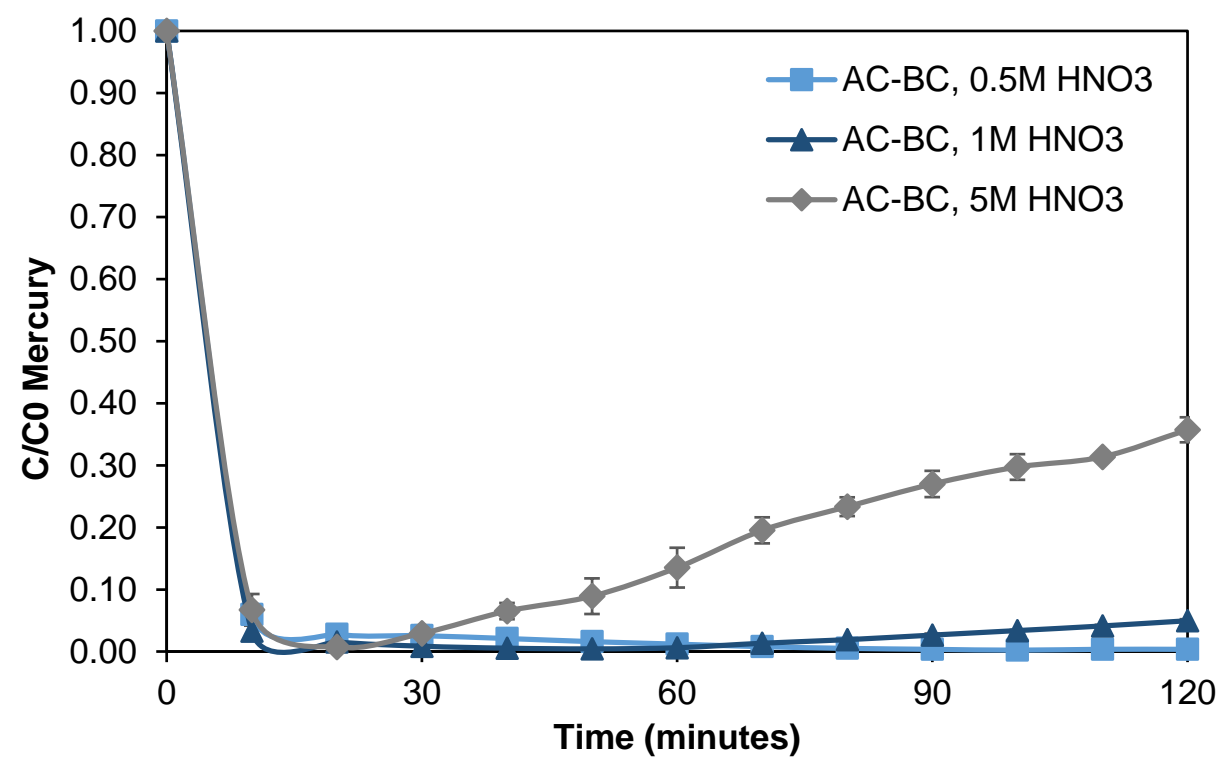

Figure 10. Mercury removal for coconut and bituminous coal-based activated carbons treated with increasing nitric acid concentrations.

\subsubsection{Hydrogen Peroxide Oxidation}

The oxidation of the activated carbons with hydrogen peroxide did not result in significant additional mercury removal as compared to the untreated counterpart for all carbon samples tested (Figure 11). Each carbon sample oxidized with hydrogen peroxide performed worse for $\mathrm{Hg}^{0}$ removal except the wood-based carbon, which only saw a slight improvement of 2-3 min of additional removal prior to breakthrough. Unlike nitric acid, hydrogen peroxide is a milder reagent that will not consume the carbon matrix as much as nitric acid or adjust the carbon structure. Therefore, it can be concluded that hydrogen peroxide treatment will solely add oxygen groups, which, in this case, can be detrimental to mercury adsorption as compared to the nitric treatment, which improved mercury removal for those carbons less like graphite (wood and coconut shell).

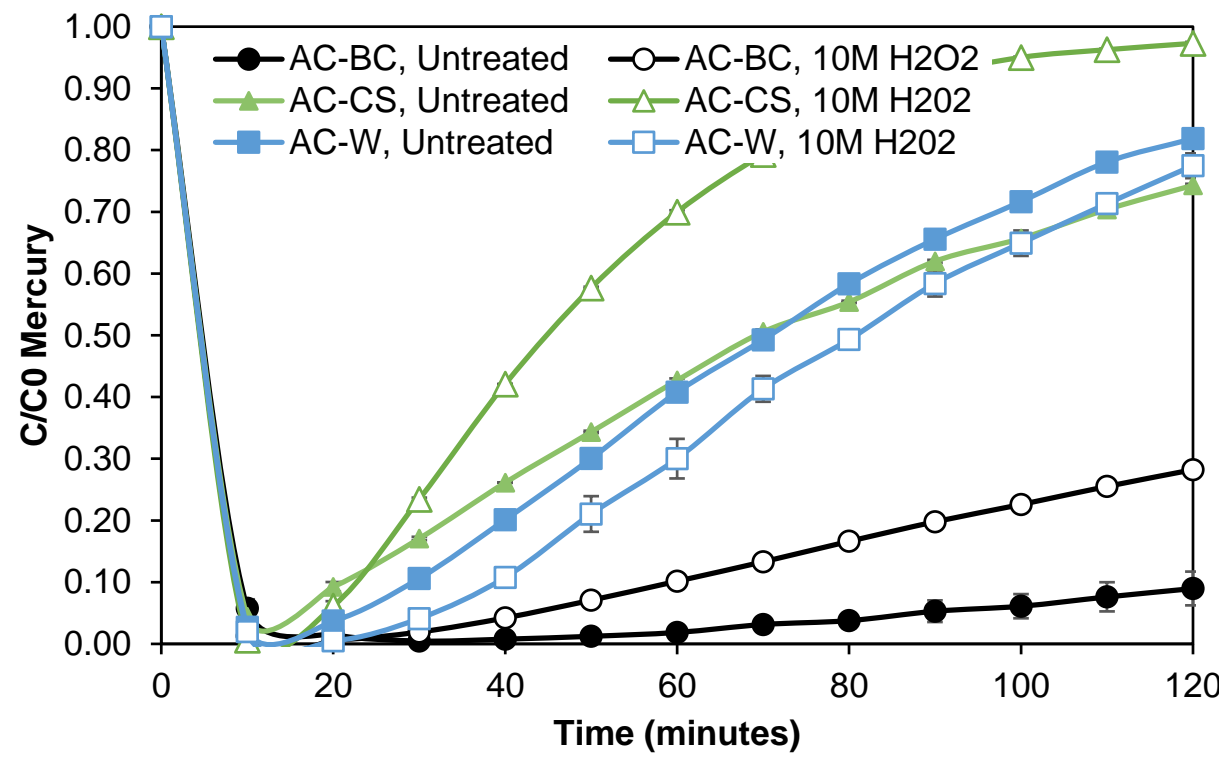

Figure 11. Mercury removal for activated carbons treated with $10 \mathrm{M}$ Hydrogen Peroxide.

\subsubsection{Creation of Carbene sites through Surface Etching}

Lizzio et al. [44] thoroughly studied the nitric treatment of activated carbon for the enhancement of free sites (i.e., carbene site) on the carbon. It was their postulation that 
carbon atoms, which are not tied up by oxygen or other atoms, have valence electrons that are more available and more reactive toward $\mathrm{SO}_{2}$ adsorption. They demonstrated a process in which activated carbons were nitric acid-treated similar to our methods and then exposed to high-temperature nitrogen gas to remove the functional groups that were added through the acid treatment. The activated carbon surface was more catalytic, and they proposed that functional group atoms were removed during the gas treatment, resulting in a larger concentration of unsaturated carbons atoms (carbene sites). This phenomenon of oxygen functional groups being removed through heat treatment has been well studied [39,56-58]; whereby, it is known that an unsaturated carbon atom is left on the surface after the heat treatment of nitrogen gas [39].

To test this for mercury removal, a similar method to Lizzio was performed on the activated carbons and tested for $\mathrm{Hg}^{0}$ adsorption. Similarly, the resultant carbons significantly improved their performance, as shown in Figure 12. Most notably, the coconut shell-based carbon that was first exposed to nitric acid and then treated with nitrogen gas had drastically improved adsorption capacity for elemental Hg. Furthermore, the bituminous coal-based carbon improved by a much larger degree, in which it continued to adsorb mercury well after any other carbons reached breakthrough.

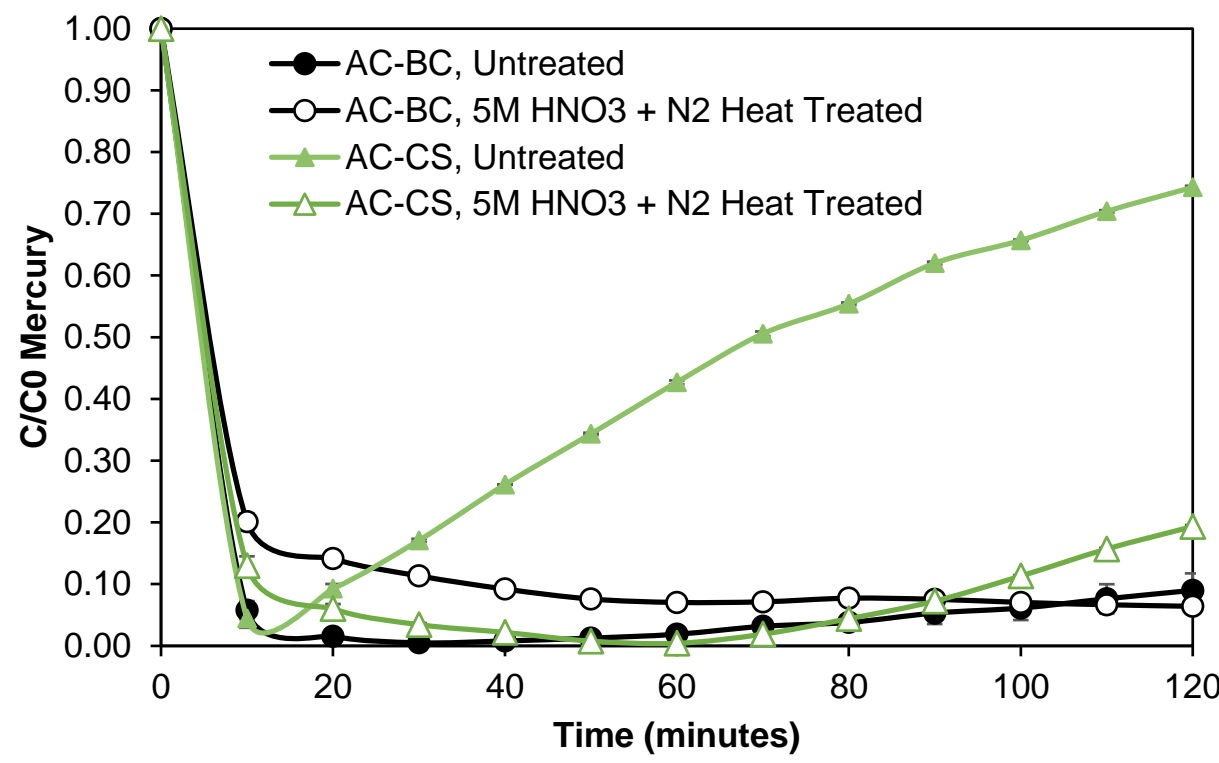

Figure 12. Mercury removal for nitric acid and nitric acid post-treated with nitrogen gas using bituminous coal-based and coconut-based activated carbons.

This drastic difference in the performance of the coconut shell-based and bituminous coal-based carbon can be further explained through the discussion of carbene sites. The aromatic structure of the bituminous coal allows for a higher capacity of carbene sites to form. Thus, when oxidized and subsequently heat-treated, the number of carbene sites present on a coal-based carbon versus a plant-based carbon, as shown above, is drastically different, lending better results to the coal-based carbons. This then also demonstrates the effectiveness of carbene sites in removing mercury, where the bituminous coal-based carbon that was further populated with free carbene sites performed best out of all the carbons in this study.

\subsection{Graphite as a Comparison for Aromatic Structure}

Graphite is a crystalline form of carbon composed of parallel layers referred to as graphene sheets. These sheets contain covalently bonded carbon atoms arranged in a hexagonal fashion with approximately 0.142 nanometers distance between each atom. The layered graphene sheets are stacked with 0.335 nanometers distance and held loosely by van der Waals forces [58]. The numerous layers are weakly connected by Van der Waals 
forces, allowing the sheets to slide on top of one another. Very similar to bituminous coal-based ACs, graphite is highly aromatic.

In a similar fashion to the activated carbons, graphite was treated with hydrogen gas and nitric acid $\left(1 \mathrm{M} \mathrm{HNO}_{3}\right)$. The resulting physical characteristics of the sorbent are detailed in Table 4. Unlike AC-BC, untreated graphite (GH) exhibited a very low surface area of $7 \mathrm{~m}^{2} / \mathrm{g}$. Hydrogen and nitric acid treatments slightly increased the surface area for both graphite samples. Nitric acid treatment lowered the $\mathrm{pH}_{\mathrm{PZC}}$ of the untreated material from a $\mathrm{pH}$ of 7.6 to 5.1 for GH-NT $\left(1 \mathrm{M} \mathrm{HNO}_{3}\right)$.

Table 4. Physical characteristics of untreated and treated graphite.

\begin{tabular}{cccc}
\hline Sample & $\begin{array}{c}\text { BET Surface Area } \\
\left(\mathbf{m}^{2} / \mathbf{g}\right)\end{array}$ & $\begin{array}{c}\text { Average Pore Size } \\
(\AA)\end{array}$ & $\begin{array}{c}\text { Total Pore Volume } \\
(\mathbf{c c} / \mathbf{g})\end{array}$ \\
\hline $\mathrm{GH}$ & 7 & 159.4 & 0.03 \\
$\mathrm{GH}-\mathrm{HT}$ & 39 & 95.9 & 0.09 \\
$\mathrm{GH}-\mathrm{NT}$ & 11 & 185.4 & 0.05 \\
$\left.(1 \mathrm{M} \mathrm{HNO})_{3}\right)$ & & & \\
\hline
\end{tabular}

Breakthrough curves and loading of elemental mercury for nitric acid, hydrogen, and untreated graphite are shown in Figure 13 and Table 5. The untreated GH experienced breakthrough shortly after 10 min while the removal for the two treated GHs markedly increased over time. Similar to the oxidized and heat-treated AC-BC sample in Figure 12, the nitric acid-treated graphite was extremely reactive to mercury adsorption and continued to remove $\mathrm{Hg}^{0}$ until breakthrough at about $600 \mathrm{~min}$ (not shown).

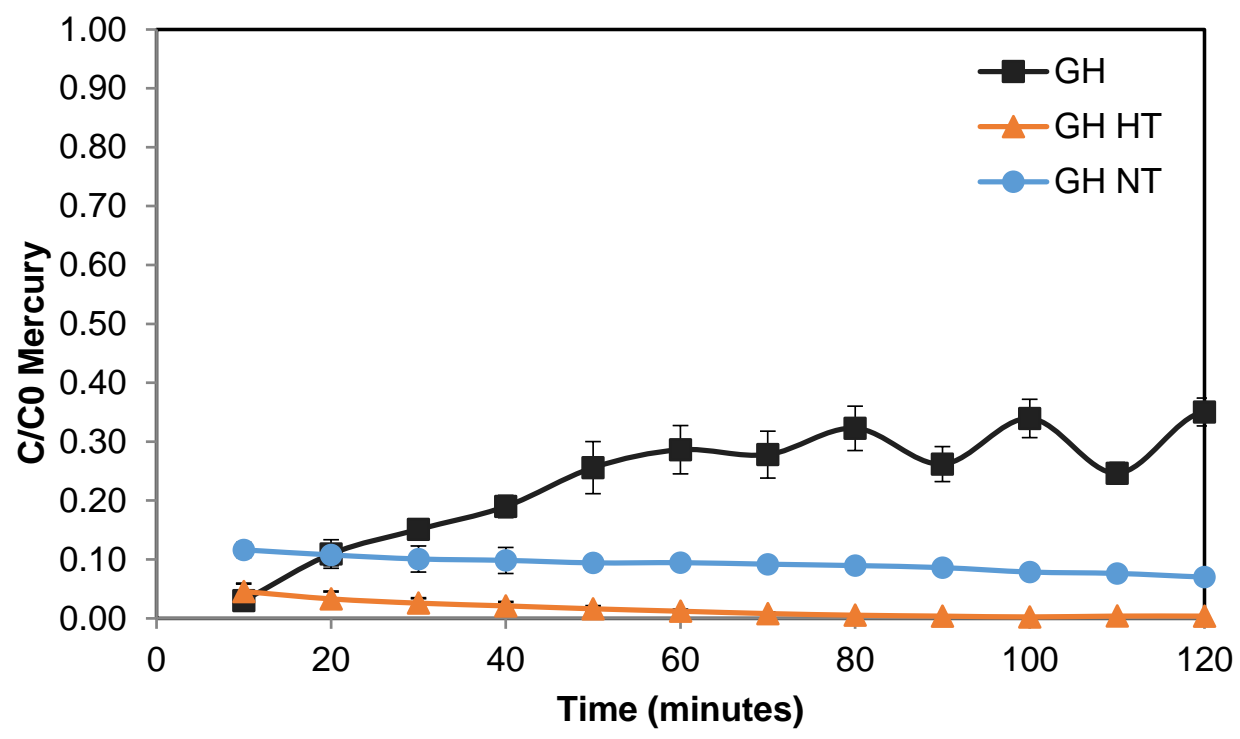

Figure 13. Elemental mercury removal for untreated and treated graphite.

The hydrogen-treated GH broke through around $120 \mathrm{~min}$. The increase in removal shown by the GH HT does not follow the same trend as for the bituminous coal-based AC. In fact, the breakthrough curve for GH HT continues to improve over time. A potential layering effect (nucleation), whereby oxidized and adsorbed mercury is participating in the removal of the influent $\mathrm{Hg}^{0}$ has been seen in other works employing silica-titania composites can begin to explain these results [59].

Another postulation for the increasing mercury removal of GH HT may be that during hydrogen treatment, the oxygen content is driven off while the carbon atoms on the edge sites are not completely annealed. As previously discussed in the work of Menendez et al. (1996), the elevated temperature would gasify oxygen and anneal the sorbent surface with hydrogen. For this material specifically, because of the nature of fully aromatic graphite material with $\sim 3 \%$ oxygen content, the postulation is that indeed 
hydrogen treatment is gasifying the oxygen, but because some of the now active sites may not all be at the edge sites, hydrogen cannot fully anneal them. This supposition is supported by the work of Redmond and Walker (1960), which concluded that the adsorption of hydrogen (by graphite) occurs on carbon atoms at the edge of crystallites and that significant intracrystalline sorption does not occur [60].

Table 5. Mercury removal comparison of bituminous coal-based activated carbon versus graphite.

\begin{tabular}{|c|c|c|c|}
\hline Sample & Carbon Raw Material & $\begin{array}{c}\mathrm{Hg}^{0} \text { Loading @ } 120 \mathrm{~min} \\
(\mathrm{ng} / \mathrm{g})\end{array}$ & $\begin{array}{c}\mathrm{Hg}^{0} \text { Loading } @ 120 \mathrm{~min} \\
\text { per Surface Area } \\
\left(\mathrm{ng} / \mathrm{m}^{2}\right)\end{array}$ \\
\hline $\mathrm{AC}-\mathrm{BC}$ & \multirow{3}{*}{ Bituminous Coal } & 2949 & 3 \\
\hline $\mathrm{AC}-\mathrm{BC} \mathrm{HT}$ & & 1641 & 2 \\
\hline $\begin{array}{l}\mathrm{AC}-\mathrm{BC} \mathrm{NT} \\
\left(1 \mathrm{M} \mathrm{HNO}_{3}\right)\end{array}$ & & 3014 & 3 \\
\hline $\mathrm{GH}$ & \multirow{3}{*}{ Graphite } & 776 & 111 \\
\hline $\mathrm{GH}-\mathrm{HT}$ & & 1005 & 26 \\
\hline $\begin{array}{c}\mathrm{GH}-\mathrm{NT} \\
\left(1 \mathrm{M} \mathrm{HNO}_{3}\right)\end{array}$ & & 926 & 82 \\
\hline
\end{tabular}

To draw further conclusions, mercury-loading for both AC-BC and GH were compared per gram of sorbent (Table 5). The results showed higher mercury-loading for the ACBC family of untreated and treated ACs. Interestingly, when the mercury-loading was normalized per $\mathrm{m}^{2}$ of available surface area, removal was two orders of magnitude higher than that of AC-BC. This finding further supports the hypothesis that materials with a higher degree of aromaticity can experience a heightened $\mathrm{Hg}^{0}$ adsorption capacity through carbene site availability.

\section{Conclusions}

The outcome of this work further showcases that the oxygen functional groups and carbene sites on the surface of activated carbon, as they relate to mercury removal, behave differently on carbons manufactured from different raw materials (coconut, wood, and bituminous coal). Overall, each carbon had some inherent functionality on the surface and, when strongly oxidized by nitric acid ( $1 \mathrm{M}$ and $5 \mathrm{M}$ ) or hydrogen peroxide, showed a decrease in performance for mercury removal. The lower performance can be explained through an understanding that carbene sites are extremely reactive sites for adsorption. When oxidation occurs through surface treatments, the carbene sites are taken up by oxygen or other heteroatoms and therefore cannot partake in $\mathrm{Hg}^{0}$ oxidation and adsorption.

The differences mentioned above are more prevalent in highly aromatic structures such as AC-BC and graphite. The results of the etched samples (AC-CS $5 \mathrm{M} \mathrm{HNO}_{3}+$ $\mathrm{NT}$ and $\mathrm{AC}-\mathrm{BC} 5 \mathrm{M} \mathrm{HNO}_{3}+\mathrm{NT}$ ) also suggest that more aromatic carbon structures can support more carbene sites and therefore have them more readily available when treated in a manner that can produce them. This was further detailed in our previous work [26]; these additional data comparing oxygen functional groups and their impacts on $\mathrm{Hg}^{0}$ adsorption show that carbene sites are necessary for $\mathrm{Hg}^{0}$ removal. Furthermore, we show that highly aromatic carbon structures can support more carbene sites.

Author Contributions: Conceptualization, R.R. and D.M.; methodology, D.C. and R.R.; validation, D.C. and R.R.; writing, D.C., R.R. and D.M.; supervision, D.M. All authors have read and agreed to the published version of the manuscript.

Funding: This material is based upon work supported by the National Science Foundation Graduate Research Fellowship under Grant No. DGE-1315138.

Institutional Review Board Statement: Not applicable.

Informed Consent Statement: Not applicable. 
Data Availability Statement: Some or all data, models, or code that support the findings of this study are available from the corresponding author upon reasonable request.

Acknowledgments: A special thanks to the various activated carbon manufacturers for supporting the goals of this research by donating activated carbon samples.

Conflicts of Interest: The authors declare no conflict of interest.

\section{References}

1. Sloss, L.L. Economics of Mercury Control; IEA Clean Coal Centre: London, UK, 2008.

2. Auzmendi-Murua, I.; Castillo, A.; Bozzelli, J.W. Mercury oxidation via chlorine, bromine, and iodine under atmospheric conditions: Thermochemistry and kinetics. J. Phys. Chem. A 2014, 118, 2959-2975. [CrossRef] [PubMed]

3. Berry, M.S. Full Scale Calcium Bromide Injection with Subsequent Mercury Oxidation and Removal within Wet Flue Gas Desulphurization System: Experience at a 700 MW Coal-Fired Power Facility; The University of Alabama at Birmingham: Birmingham, AL, USA, 2012.

4. Dranga, B.A.; Lazar, L.; Koeser, H. Oxidation Catalysts for Elemental Mercury in Flue Gases-A Review atalysts. Catalysts 2012, 2, 139. [CrossRef]

5. Qu, Z.; Yan, N.; Liu, P.; Chi, Y.; Jia, J. Bromine chloride as an oxidant to improve elemental mercury removal from coal-fired flue gas. Environ. Sci. Technol. 2009, 43, 8610-8615. [CrossRef]

6. Pavlish, H.J.; Hamre, L.L.; Zhuang, Y. Mercury control technologies for coal combustion and gasification systems. Fuel 2010, 89, 838. [CrossRef]

7. Shewchuk, S.; Azargohar, R.; Dalaia, K. Elemental mercury capture using activated carbon: A review. J. Environ. Anal. Toxicol. 2016, 6, 1-10. [CrossRef]

8. Reddy, B.M.; Durgasri, N.; Kumar, T.V.; Bhargava, S.K. Abatement of gas-phase mercury-Recent developments. Catal. Rev. 2012, 54, 344-398. [CrossRef]

9. Skodras, G.; Diamantopoulou, I.; Zabaniotou, A.; Stavropoulos, G.; Sakellaropoulos, G. Enhanced mercury adsorption in activated carbons from biomass materials and waste tires. Fuel Process. Technol. 2007, 88, 749-758. [CrossRef]

10. Skodras, G.; Diamantopoulou, I.; Pantoleontos, G.; Sakellaropoulos, G. Kinetic studies of elemental mercury adsorption in activated carbon fixed bed reactor. J. Hazard. Mater. 2008, 158, 1-13. [CrossRef]

11. Diamantopoulou, I.; Skodras, G.; Sakellaropoulos, G. Sorption of mercury by activated carbon in the presence of flue gas components. Fuel Process. Technol. 2010, 91, 158-163. [CrossRef]

12. Vidic, R.D.; Siler, D.P. Vapor-phase elemental mercury adsorption by activated carbon impregnated with chloride and chelating agents. Carbon 2001, 31, 3-14. [CrossRef]

13. Rupp, E.C.; Wilcox, J. Mercury chemistry of brominated activated carbons-packed-bed breakthrough experiments. Fuel 2014, 117, 351-353. [CrossRef]

14. Saha, A.; Abram, D.N.; Kuhl, K.P.; Paradis, J.; Crawford, J.L.; Sasmaz, E.; Chang, R.; Jaramillo, T.F.; Wilcox, J. An X-ray photoelectron spectroscopy study of surface changes on brominated and sulfur-treated activated carbon sorbents during mercury capture: Performance of pellet versus fiber sorbents. Environ. Sci. Technol. 2013, 47, 13695-13701. [CrossRef]

15. Sasmaz, E.; Kirchofer, A.; Jew, A.D.; Saha, A.; Abram, D.; Jaramillo, T.F.; Wilcox, J. Mercury chemistry on brominated activated carbon. Fuel 2012, 99, 188-196. [CrossRef]

16. Granite, E.J.; Pennline, H.W.; Hargis, R.A. Sorbents for Mercury Removal from Flue Gas; U.S. Department of Energy: Pittsburgh, PA, USA, 1998.

17. Granite, E.J.; Pennline, H.W.; Hargis, R.A. Novel sorbents for mercury removal from flue gas. Ind. Eng. Chem. Res. 2000, 39, 1020-1029. [CrossRef]

18. Li, Y.H.; Lee, C.W.; Gullett, B.K. Importance of activated carbon's oxygen surface functional groups on elemental mercury adsorption. Fuel 2003, 82, 451. [CrossRef]

19. Faulconer, E.K.; Mazyck, D.W. Influence of activated carbon surface oxygen functionality on elemental mercury adsorption from aqueous solution. J. Environ. Chem. Eng. 2017, 7, 2879-2885. [CrossRef]

20. Li, N.; Ma, X.; Zha, Q.; Kim, K.; Chen, Y.; Song, C. Maximizing the number of oxygen-containing functional groups on activated carbon by using ammonium persulfate and improving the temperature-programmed desorption characterization of carbon surface chemistry. Carbon 2011, 49, 5002-5013. [CrossRef]

21. Karatza, D.; Lancia, A.; Prisciandaro, M.; Musmarra, D.; Di Celso, G.M. Influence of oxygen on adsorption of elemental mercury vapors onto activated carbon. Fuel 2013, 111, 485-491. [CrossRef]

22. Leon y Leon, C.A.; Radovic, L.R. Influence of Oxygen Functional Groups on the Performance of Carbon-Supported Catalysts. In Abstracts of Papers of the American Chemical Society; American Chemical Society: Washington, DC, USA, $1991 ;$ p. 1007.

23. Jaramillo, J.; Álvarez, P.M.; Gómez-Serrano, V. Preparation and ozone-surface modification of activated carbon. Thermal stability of oxygen surface groups. Appl. Surf. Sci. 2010, 256, 5232. [CrossRef]

24. Walker, P., Jr.; Austin, L.; Tietjen, J. Chemisorption of oxygen on graphite as followed by thermoelectric power measurements. Carbon 1965, 2, 434-436. [CrossRef] 
25. Olson, E.S.; Laumb, J.D.; Benson, S.A.; Dunham, G.E.; Sharma, R.K.; Mibeck, B.A.; Miller, S.J.; Holmes, M.J.; Pavlish, J.H. The Mechanism for Chemisorption of Elemental Mercury on Activated Carbons in Flue Gas; 2004. Available online: https: //www.researchgate.net/profile/Blaise-Mibeck/publication/267382254_THE_MECHANISM_FOR_CHEMISORPTION_ OF_ELEMENTAL_MERCURY_ON_ACTIVATED_CARBONS_IN_FLUE_GAS/links/546e1a330cf2bc99c2151f2f/THEMECHANISM-FOR-CHEMISORPTION-OF-ELEMENTAL-MERCURY-ON-ACTIVATED-CARBONS-IN-FLUE-GAS.pdf (accessed on 7 July 2021).

26. Rodriguez, R.; Contrino, D.; Mazyck, D.W. Role of Activated Carbon Precursor in Mercury Removal. Ind. Eng. Chem. Res. 2020, 59, 17740-17747. [CrossRef]

27. Hsi, H.; Rood, M.J.; Rostam-Abadi, M.; Chang, Y. Effects of sulfur, nitric acid, and thermal treatments on the properties and mercury adsorption of activated carbons from bituminous coals. Aerosol Air Qual. Res. 2013, 13, 730. [CrossRef]

28. Maroto-Valer, M.M.; Zhang, Y.; Granite, E.J.; Tang, Z.; Pennline, H.W. Effect of porous structure and surface functionality on the mercury capacity of a fly ash carbon and its activated sample. Fuel 2005, 84, 105-108. [CrossRef]

29. Radovic, L.R. The mechanism of $\mathrm{CO}_{2}$ chemisorption on zigzag carbon active sites: A computational chemistry study. Carbon 2005, 43, 907-915. [CrossRef]

30. Radovic, L.R.; Bockrath, B. What exactly is on the edges of graphene layers in carbon: The unfolding story. Prepr. Pap. Am. Chem. Soc. Div. Fuel Chem. 2002, 47, 428-431.

31. Olson, E.S.; Miller, S.J.; Sharma, R.K.; Dunham, G.E.; Benson, S.A.; Olson, E.S. Catalytic effects of carbon sorbents for mercury capture. J. Hazard. Mater. 2000, 74, 61. [CrossRef]

32. Olson, E.S.; Laumb, J.D.; Benson, S.A.; Dunham, G.E.; Sharma, R.K.; Miller, S.J.; Pavlish, J.H. The multiple site model for flue gas Mercury interactions on activated carbons: The Basic Site. Fuel Chem. Div. Prepr. 2003, 48, 1.

33. Olson, E.S.; Mibeck, B.A.; Benson, S.A.; Laumb, J.D.; Crocker, C.R.; Dunham, G.E.; Sharma, R.K.; Miller, S.J.; Pavlish, J.H. The mechanistic model for flue gas-mercury interactions on activated carbons: The oxidation site. Prepr. Pap. Am. Chem. Soc. Div. Fuel Chem. 2004, 49, 279.

34. Olson, E.S.; Azenkeng, A.; Laumb, J.D.; Jensen, R.R.; Benson, S.A.; Hoffmann, M.R. New developments in the theory and modeling of mercury oxidation and binding on activated carbons in flue gas. Fuel Process. Technol. 2009, 90, 1360. [CrossRef]

35. Wilcox, J.; Sasmaz, E.; Kirchofer, A.; Lee, S. Heterogeneous mercury reaction chemistry on activated carbon. J. Air Waste Manag. Assoc. 2011, 61, 418-426. [CrossRef]

36. Padak, B.; Brunetti, M.; Lewis, A.; Wilcox, J. Mercury binding on activated carbon. Environ. Prog. 2006, 25, 319-326. [CrossRef]

37. Padak, B.; Wilcox, J. Understanding mercury binding on activated carbon. Carbon 2009, 47, 2855-2864. [CrossRef]

38. Wilcox, J.; Rupp, E.; Ying, S.C.; Lim, D.H.; Negreira, A.S.; Kirchofer, A.; Feng, F.; Lee, K. Mercury adsorption and oxidation in coal combustion and gasification processes. Int. J. Coal Geol. 2012, 90, 4-20. [CrossRef]

39. Menéndez, J.A.; Phillips, J.; Xia, B.; Radovic, L.R. On the modification and characterization of chemical surface properties of activated carbon: In the search of carbons with stable basic properties. Langmuir 1996, 12, 4404-4410. [CrossRef]

40. Li, Y.H.; Lee, C.W.; Gullett, B.K. The effect of activated carbon surface moisture on low temperature mercury adsorption. Carbon 2002, 40, 65. [CrossRef]

41. Hall, B.; Schager, P.; Weesmaa, J. The homogeneous gas phase reaction of mercury with oxygen, and the corresponding heterogeneous reactions in the presence of activated carbon and fly ash. Chemosphere 1995, 30, 611-627. [CrossRef]

42. Lee, S.; Park, Y. Gas-phase mercury removal by carbon-based sorbents. Fuel Process. Technol. 2003, 84, 197-206. [CrossRef]

43. Kwon, S.; Borguet, E.; Vidic, R. Impact of surface heterogeneity on mercury uptake by carbonaceous sorbents under UHV and atmospheric pressure. Environ. Sci. Technol. 2002, 36, 4162-4169. [CrossRef]

44. Lizzio, A.A.; DeBarr, J.A. Mechanism of SO2 removal by carbon. Energy Fuels 1997, 11, 284-291. [CrossRef]

45. University of Colorado Boulder. Table of Characteristic IR Absorptions. Available online: https://www.orgchemboulder.com/ Spectroscopy/irtutor/tutorial.shtml (accessed on 7 July 2021).

46. Pavia, D.L.; Lampman, G.M.; Kriz, G.S.; Vyvyan, J.A. Introduction to Spectroscopy; Cengage Learning: Boston, MA, USA, 2014.

47. Boehm, H.P.; Diehl, E.; Heck, W.; Sappok, R. Surface oxides of carbon. Angew. Chem. Int. Ed. Engl. 1964, 3, 669. [CrossRef]

48. Fidel, R.B.; Laird, D.A.; Thompson, M.L. Evaluation of Modified Boehm Titration Methods for Use with Biochars. J. Environ. Qual. 2013, 42, 1771-1778. [CrossRef]

49. Goertzen, S.L.; Thériault, K.D.; Oickle, A.M.; Tarasuk, A.C.; Andreas, H.A. Standardization of the Boehm Titration. Part I. CO 2 Expulsion and Endpoint Determination. Carbon 2010, 48, 1252-1261. [CrossRef]

50. Oickle, A.M.; Goertzen, S.L.; Hopper, K.R.; Abdalla, Y.O.; Andreas, H.A. Standardization of the Boehm Titration: Part II. Method of Agitation, Effect of Filtering and Dilute Titrant. Carbon 2010, 48, 3313-3322. [CrossRef]

51. Barkauskas, J.; Dervinyte, M. An investigation of the functional groups on the surface of activated carbons. J. Serb. Chem. Soc. 2004, 69, 363. [CrossRef]

52. Gómez-Serrano, V.; Piriz-Almeida, F.; Durán-Valle, C.J.; Pastor-Villegas, J. Formation of oxygen structures by air activation. A study by FT-IR spectroscopy. Carbon 1999, 37, 1517-1528. [CrossRef]

53. Li, L.; Li, X.; Lee, J.; Keener, T.C.; Liu, Z.; Yao, X. The effect of surface properties in activated carbon on mercury adsorption. Ind. Eng. Chem. Res. 2012, 51, 9136-9144. [CrossRef]

54. Kim, B.; Bae, K.; An, K.; Park, S. Elemental mercury adsorption behaviors of chemically modified activated carbons. Bull. Korean Chem. Soc. 2011, 32, 1321-1326. [CrossRef] 
55. Salame, I.I.; Bandosz, T.J. Surface Chemistry of Activated Carbons Combining the Results of Temperature Programmed Desorption, Boehm, And Potentiometric Titrations. J. Colloid Interface Sci. 2001, 240, 252-258. [CrossRef] [PubMed]

56. Moreno-Castilla, C.; Ferro-Garcia, M.A.; Joly, J.P.; Bautista-Toledo, I.; Carrasco-Marin, F.; Rivera-Utrilla, J. Activated carbon surface modifications by nitric acid, hydrogen peroxide, and ammonium peroxydisulfate treatments. Langmuir 1995, 11, $4386-4392$. [CrossRef]

57. Moreno-Castilla, C.; López-Ramón, M.V.; Carrasco-Marın, F. Changes in surface chemistry of activated carbons by wet oxidation. Carbon 2000, 38, 1995-2001. [CrossRef]

58. Rodriguez-Reinoso, F.; Molina-Sabio, M.; Munecas, M.A. Effect of microporosity and oxygen surface groups of activated carbon in the adsorption of molecules of different polarity. J. Phys. Chem. 1992, 96, 2707-2713. [CrossRef]

59. Stokke, J.M.; Mazyck, D.W. Development of a regenerable system employing silica-titania composites for the recovery of mercury from end-box exhaust at a chlor-alkali facility. J. Air Waste Manag. Assoc. 2008, 58, 530-537. [CrossRef] [PubMed]

60. Redmond, J.P.; Walker, P., Jr. Hydrogen Sorption on Graphite at Elevated Temperatures1, 2. J. Phys. Chem. 1960, 64, 1093-1099. [CrossRef] 